\title{
Microbiome and antimicrobial resistance genes in microbiota of cloacal samples from European herring gulls (Larus argentatus)
}

\author{
Lina Merkeviciene, Neda Ruzauskaite, Irena Klimiene, \\ Rita Siugzdiniene, Jurgita Dailidaviciene, Marius Virgailis, \\ Raimundas Mockeliunas, Modestas Ruzauskas \\ Lithuanian University of Health Sciences, LT-44307 Kaunas, Lithuania \\ modestas.ruzauskas@1smuni.lt
}

Received: August 27, 2016

Accepted: March 6, 2017

\begin{abstract}
Introduction: The aim of the study was to determine microbiota in the cloacal samples of European herring gulls (Larus argentatus) and to compare a variety of genes encoding antimicrobial resistance in cultivable and non-cultivable bacteria. Material and Methods: Cloacal samples from European herring gulls were collected from a Kaunas city dump. Cultivable microbiota were isolated, their microbial susceptibility was tested, and genes encoding antimicrobial resistance were detected. Additionally, a metagenomic study was performed using Next-Generation Sequencing (NGS). Results: In total, 697 different operational taxonomic units at genus level were detected; however, only 63 taxonomic units were detected at the amount of $\geq 0.1 \%$ of the total number of DNA copies. Catellicoccus marimammalium was found to have the highest prevalence. The bacterial amount of other genera was up to 5\% with the most highly prevalent being Psychrobacter (4.7\%), Helicobacter (4.5\%), unclassified Enterococcaceae (3.2\%), Pseudomonas (2.9\%), and Brachyspira (2.6\%). Conclusions: C. marimammalium are predominant microbiota in the cloacal samples of Larus argentatus. This species of gulls is a reservoir of bacteria carrying a wide-spectrum of genes encoding antimicrobial resistance. The same genes were detected in both cultivable microbiota and in the total DNA of the samples.
\end{abstract}

Keywords: European herring gulls, Catellicoccus, microbiome, antimicrobial resistance, genes.

\section{Introduction}

The random use of antimicrobial agents causes microorganisms to acquire antimicrobial resistance (AMR). These microorganisms may be shed in animal and human faeces and contaminate soil, food, and aquatic environments (20). Despite increasing public health concerns about the potential risks associated with swimming in waters contaminated with waterfowl faeces, little is known about the composition of the gut microbial community of aquatic birds (8). Wild birds are important with regard to antibiotic resistance in several different ways: 1) birds are indicators of human activity and human impact on the environment and can easily pick up human and environmental bacteria during their feeding; 2) birds are a reservoir and melting pot of antibiotic-resistant bacteria and resistance genes; 3) birds can spread antibiotic resistance through the ability to migrate long distances in short periods; 4) birds are a possible source of antibiotic-resistance bacteria that colonise and/or infect human beings (2).

Some bird species live near humans or farms and there is a risk of spreading antimicrobial resistance. The contraction of natural habitats due to anthropogenic factors may change the behaviour of certain animal species including birds. Gulls are a good example of how marine birds have changed their lifestyle due to human activity. Some species of gulls, like Larus ridibundus, L. argentatus, and L. cacchinnans, have changed their feeding behaviour dramatically. They are abundant in urban landfill sites where they feed more easily than in their natural feeding places on the water. Although wild birds have only rare contact with antimicrobial agents, in contrast to the presence of direct selective pressure, they can be 
contaminated or colonised by resistant bacteria (5). Gulls, however, may have direct contact with antimicrobials or other chemicals because they feed in municipal dumps. Recent findings of the $m c r-1$ gene encoding plasmid-mediated resistance to colistin in cultivable microbiota of gulls on two different continents suggest that more studies on the microbiota in this genus of birds is needed. These studies intend to investigate the presence of other genes encoding resistance to different classes of antimicrobials in gull gut $(7,17)$.

It is well known that cultivable gut microbiota constituents such as Escherichia coli and enterococci can acquire and transfer genes encoding antimicrobial resistance. These commensal bacteria are a reservoir of resistance genes for pathogenic bacteria, and they indicate changes in antimicrobial resistance (3). Phenotypic and genotypic resistance in the cultivable microbiota of wild birds has been investigated previously $(12,21,23)$. However, there is insufficient data about non-cultivable bacterial species and their role as reservoirs of genes that encode antimicrobial resistance. Recent techniques facilitate the study of non-cultivable microbiota. Such a study can explain its role as a reservoir of antimicrobial resistance.

The aim of this study was to determine the microbiota (with the focus on clinically important and AMR-genotypic species) in cloacal samples of European herring gulls (Larus argentatus) and to compare genes encoding antimicrobial resistance in cultivable and non-cultivable bacteria.

\section{Material and Methods}

Sampling. The material was collected at Kaunas city dump, where cloacal swabs from European herring gulls were collected using the catching method. The birds were selected randomly from the large flock (approximately 450 birds) including four different species of gulls (Larus argentatus, L. ridibundus, L. cachinnans, and L. marinus). The sampling was performed in December 2015. Ten individual samples were taken from five unsexed adults and five unsexed juvenile/subadult (2-4 years old) birds. Swabs were placed into transport medium (Transwab, MWE, UK) and delivered to the laboratory within $2 \mathrm{~h}$.

Bacteriological and antimicrobial susceptibility testing. A part of each cloacal sample was used for direct inoculation onto selective nutrient media while the rest of the sample was used for extraction of total DNA. The following media were used: for Enterobacteriaceae - eosin methylene blue agar (Thermo Scientific, UK), for staphylococci - mannitol salt agar (Thermo Scientific), for enterococci - Slanetz and Bartley agar (Thermo Scientific), and for Pseudomonas spp. - cetrimide agar (Thermo Scientific). The samples were incubated at $35^{\circ} \mathrm{C}$ for $24 \mathrm{~h}$. The predominant colonies from the selective media were then selected for identification and antimicrobial susceptibility testing. Fifty separate and well-isolated colonies (five from each gull sample) were selected and re-inoculated onto tryptic soy agar at $35^{\circ} \mathrm{C}$ for $18 \mathrm{~h}$ to obtain pure cultures. If different phenotypes were expressed on the nutrient media (i.e. mannitol-positive and negative staphylococci and tetrazolium-positive and negative enterococci), isolates of both phenotypes were selected.

Taxonomic identification was performed using Microbact biochemical testing systems and ERICTM software (Thermo Scientific, UK). From the 50 isolates tested, the following genera were identified and used for phenotypical antimicrobial susceptibility testing: Escherichia (16 isolates), Klebsiella (4 isolates), Enterobacter (4 isolates), Acinetobacter (4 isolates), Pseudomonas (2 isolates), Staphylococcus (10 isolates), and Enterococcus (10 isolates). Antimicrobial susceptibility testing was performed using the KirbyBauer disk diffusion method (1). The following antimicrobial disks were used, selected under Clinical and Laboratory Standards Institute guidelines (4): penicillin G, oxacillin, cefpodoxime, ceftazidime, cefotaxime, tetracycline, sulphamethoxazoletrimethoprim, streptomycin, kanamycin, gentamicin, erythromycin, lincomycin, ciprofloxacin, and chloramphenicol. Interpretation of the results was based on CLSI clinical breakpoints (4). The isolates demonstrating resistance above the clinical breakpoints were used to detect the respective genes encoding antimicrobial resistance.

Metagenomics and microbial profiling analysis. The DNA from each cloacal swab was purified using a faecal DNA MiniPrep kit (D6010, Zymo Research, USA) and pooled into one sample. The sample was purified using a DNA Clean \& Concentrator-25 kit (Zymo Research) to produce at least $50 \mathrm{ng} / \mu \mathrm{L}$ DNA. Metagenomic libraries were prepared, sequenced, quality controlled, and assembled in an independent service laboratory (Baseclear, the Netherlands). Short paired sequence reads were generated using the Illumina MiSeq system (Illumina, USA) and converted into FASTQ files using the BCL2FASTQ pipeline software, version 1.8.3 (Illumina). Quality trimming was applied based on Phred quality scores. Subsequently, the Illumina paired reads were merged into single reads (so-called "pseudoreads") through sequence overlap. Chimeric pseudoreads were removed, and the remaining reads were aligned to a combination of the GreenGenes and RDP 16S gene databases. Based on the alignment scores of the pseudoreads, the taxonomic classes were assigned by associating each pseudoread to the best matching Operational Taxonomic Unit (OTU). The results of the taxonomic classification were presented on the interactive online platform https://metagenomics. baseclear.com.

Detection of genes encoding antimicrobial resistance and data analysis. Genes encoding 
antimicrobial resistance were investigated both in selected bacterial isolates and in the total DNA from the cloacal samples. Genes from the bacterial cultures were analysed in the DNA obtained after bacterial lysis that was performed as described previously with slight modifications (14). Briefly, cultures were grown on tryptic soy agar (Liofilchem, Italy) for $24 \mathrm{~h}$ and afterwards a loopful of colonies was taken from the surface of the agar and transferred to phosphate buffered saline ( $\mathrm{pH} 7.3$ ). The content was centrifuged for $5 \mathrm{~min}$, the supernatant was discarded and the pellet was re-suspended in Tris-EDTA (TE) buffer. The suspension was heated using a thermomixer at $100^{\circ} \mathrm{C}$ for $10 \mathrm{~min}$. The boiled suspension was transferred directly onto ice and diluted to 1:10 in nuclease-free water. For detection of the genes in the total DNA, the same DNA extracts were used as for the metagenomic study. A variety of genes encoding resistance in Grampositive and Gram-negative bacteria were investigated as described previously $(15,16,18,19)$. Briefly, a PCR using specific primers for genes encoding antimicrobial resistance was performed using Dream Taq Green PCR Master Mix (Thermo Fisher, Lithuania). The genes of interest are presented in Table 2. The presence of the genes in cultivable microbiota isolated from gulls was compared to the presence of genes in total DNA representing both cultivable and non-cultivable bacterial DNA.

\section{Results}

Microbiota prevalence in the cloacal samples of European herring gulls. The composition of microbiota in the cloacal samples of European herring gulls determined in the metagenomic study is presented in Table 1 .

Table 1. Microbiota composition in the cloacal samples of European herring gulls

\begin{tabular}{|c|c|c|}
\hline Taxonomic unit* & Number of reads & Prevalence \\
\hline Catellicoccus & 38915 & $51.36 \%$ \\
\hline Psychrobacter & 3542 & $4.67 \%$ \\
\hline Helicobacter & 3405 & $4.49 \%$ \\
\hline unclassified Enterococcaceae & 2395 & $3.16 \%$ \\
\hline Pseudomonas & 2184 & $2.88 \%$ \\
\hline Brachyspira & 1943 & $2.56 \%$ \\
\hline Carnobacterium & 1721 & $2.27 \%$ \\
\hline Enterococcus & 1664 & $2.19 \%$ \\
\hline Macrococcus & 1443 & $1.90 \%$ \\
\hline Lactobacillus & 1284 & $1.69 \%$ \\
\hline Clostridium & 1043 & $1.37 \%$ \\
\hline Cetobacterium & 970 & $1.28 \%$ \\
\hline Candidatus Arthromitus & 892 & $1.17 \%$ \\
\hline Streptococcus & 867 & $1.14 \%$ \\
\hline Arthrobacter & 716 & $0.94 \%$ \\
\hline Escherichia & 629 & $0.83 \%$ \\
\hline unclassified Lactobacillales & 587 & $0.77 \%$ \\
\hline Brochothrix & 513 & $0.67 \%$ \\
\hline Corynebacterium & 476 & $0.62 \%$ \\
\hline Vagococcus & 445 & $0.58 \%$ \\
\hline Staphylococcus & 332 & $0.43 \%$ \\
\hline unclassified Staphylococcaceae & 305 & $0.40 \%$ \\
\hline Rothia & 279 & $0.36 \%$ \\
\hline unclassified Lactobacillaceae & 270 & $0.35 \%$ \\
\hline unclassified Listeriaceae & 253 & $0.33 \%$ \\
\hline Campylobacter & 220 & $0.29 \%$ \\
\hline Mycobacterium & 212 & $0.27 \%$ \\
\hline Bacillus & 210 & $0.27 \%$ \\
\hline
\end{tabular}


Table 1 (continued)

\begin{tabular}{|c|c|c|}
\hline unclassified Gammaproteobacteria & 187 & $0.24 \%$ \\
\hline Trichococcus & 168 & $0.22 \%$ \\
\hline unclassified Carnobacteriaceae & 164 & $0.21 \%$ \\
\hline unclassified Bacilli & 161 & $0.21 \%$ \\
\hline Yersinia & 154 & $0.20 \%$ \\
\hline Weissella & 154 & $0.20 \%$ \\
\hline unclassified Bacillales & 151 & $0.19 \%$ \\
\hline Brachybacterium & 141 & $0.18 \%$ \\
\hline unclassified Clostridiales & 140 & $0.18 \%$ \\
\hline Lactococcus & 136 & $0.17 \%$ \\
\hline Klebsiella & 135 & $0.17 \%$ \\
\hline Saccharopolyspora & 134 & $0.17 \%$ \\
\hline Leuconostoc & 127 & $0.16 \%$ \\
\hline Desemzia & 125 & $0.16 \%$ \\
\hline unclassified Pseudomonadales & 115 & $0.15 \%$ \\
\hline Jeotgalicoccus & 107 & $0.14 \%$ \\
\hline unclassified Epsilonproteobacteria & 107 & $0.14 \%$ \\
\hline unclassified Moraxellaceae & 100 & $0.13 \%$ \\
\hline unclassified Streptococcaceae & 98 & $0.12 \%$ \\
\hline Acinetobacter & 97 & $0.12 \%$ \\
\hline Aerosphaera & 96 & $0.12 \%$ \\
\hline Planomicrobium & 92 & $0.12 \%$ \\
\hline Planococcus & 92 & $0.12 \%$ \\
\hline Aerococcus & 90 & $0.11 \%$ \\
\hline unclassified Actinobacteria & 90 & $0.11 \%$ \\
\hline Turicibacter & 84 & $0.11 \%$ \\
\hline Enterobacter & 83 & $0.10 \%$ \\
\hline Methylocaldum & 83 & $0.10 \%$ \\
\hline unclassified Clostridiaceae & 81 & $0.10 \%$ \\
\hline Bifidobacterium & 81 & $0.10 \%$ \\
\hline unclassified Actinobacteridae & 81 & $0.10 \%$ \\
\hline Peptoclostridium & 80 & $0.10 \%$ \\
\hline Brevibacterium & 77 & $0.10 \%$ \\
\hline unclassified Mycoplasmatales & 76 & $0.10 \%$ \\
\hline unclassified Bacillaceae & 76 & $0.10 \%$ \\
\hline Other genera (with prevalence less than $0.1 \%$ ) & 4078 & $5.38 \%$ \\
\hline
\end{tabular}

* Table contains only those taxonomic units (genera, families) whose prevalences in the samples were $0.1 \%$ and above

A wide variety of the microorganisms were found in the cloacal samples of gulls. The total amount of different taxonomic units at the genus (or higher rank) level was 697, although 339 taxonomic units had less than 3 reads, i.e. only 1 or 2 copies of appropriate specific DNA. Table 1 shows that Catellicoccus was the most prevalent genus. This genus represents half of all bacteria within the cloacal samples. The most prevalent species in this genus was C. marimamalium (79\%). Unclassified Catellicoccus constituted the rest of the species. The bacterial amount of all other genera was less than $5 \%$ with the most highly prevalent being Psychrobacter (4.7\%), Helicobacter (4.5\%), unclassified Enterococcaceae (3.2\%), Pseudomonas (2.9\%), and Brachyspira (2.6\%).

The prevalence of clinically important bacteria.

Enterobacteriaceae. The prevalence of the Enterobacteriaceae family in the cloacal samples of the birds was $2 \%$ of the total amount of bacteria. The composition of the family is presented in Fig. 1. 
At least 21 genera of Enterobacteriaceae were detected in the cloacal samples of the gulls (Fig. 1). The most prevalent bacteria of this family belonged to the Escherichia genus (54\%), with lower prevalences of Yersinia (13\%), Klebsiella (12\%), and Enterobacter (7\%). Salmonella was detected at low levels (three copies of DNA).

Staphylococcus spp. Staphylococcus comprised $0.43 \%$ of the total amount of bacteria. The most prevalent species in this genus were $S$. equorum (51\%) and S. saprophyticus (8\%). S. aureus comprised only $1 \%$ of all staphylococci. Other bacteria of Staphylococcus genus which were unclassified made up a $20 \%$ proportion (Fig. 2).

Enterococcus spp. The prevalence of the Enterococcus genus was 2.2\%. Most enterococci (84\%) could not be classified, although 13 different species were detected, with the highest prevalence among them appertaining to E aquimarinus (10\%) (Fig. 3). E. faecium and E. faecalis comprised $4 \%$ and $1 \%$ of the total enterococci, respectively.

Campylobacter spp. and Brachyspira spp. Campylobacter accounted for $0.3 \%$ of the total amount of bacteria. The most prevalent species were $C$. lari (49\%) and $C$. peloridis $(36 \%)$, while $C$. jejuni comprised $6 \%$ of all campylobacters. Brachyspira were prevalent at $2.6 \%$ of the total bacterial load. The most prevalent species were B. corvi $(82 \%)$ and B. pilosicoli (11\%).

Clostridium spp. Clostridium was the genus of $1.4 \%$ of bacteria. C. perfringens prevailed (54\%) but 22 other species of this genus were identified (Fig. 4).

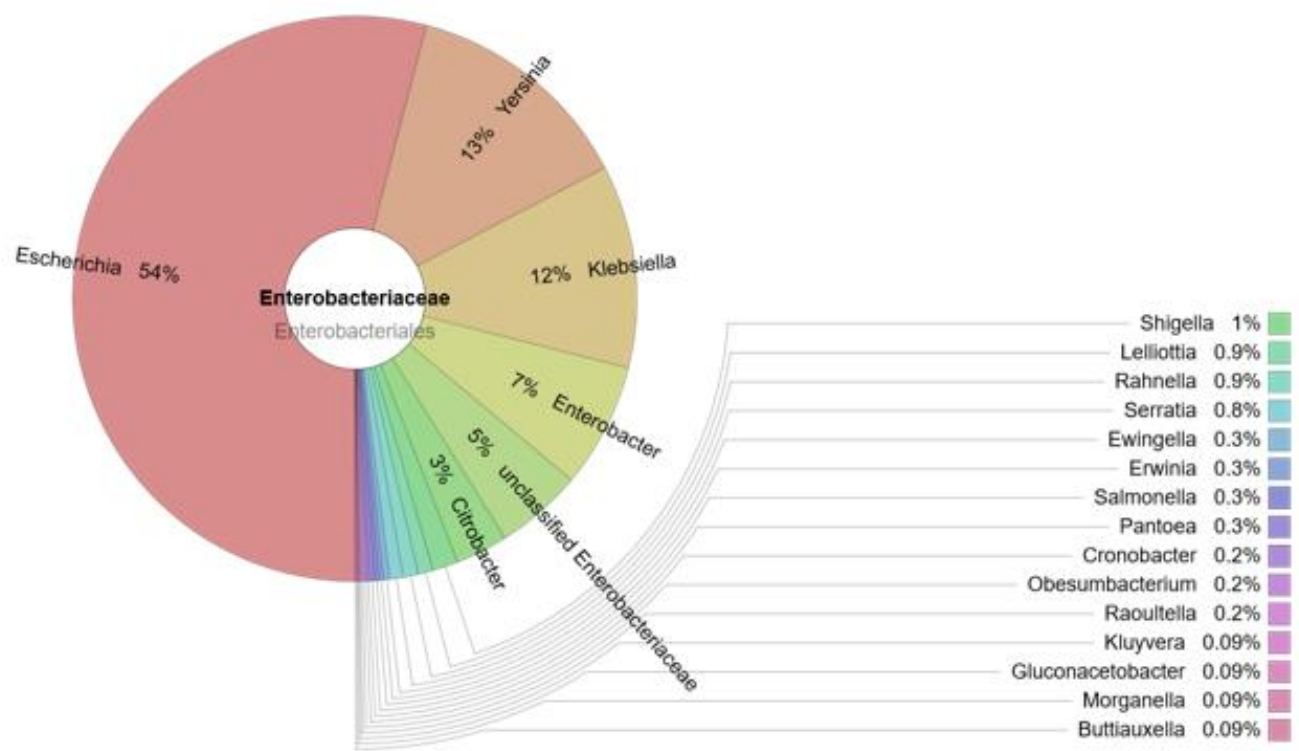

Fig. 1. The prevalence of bacteria of Enterobacteriaceae family in the cloacal samples of gulls

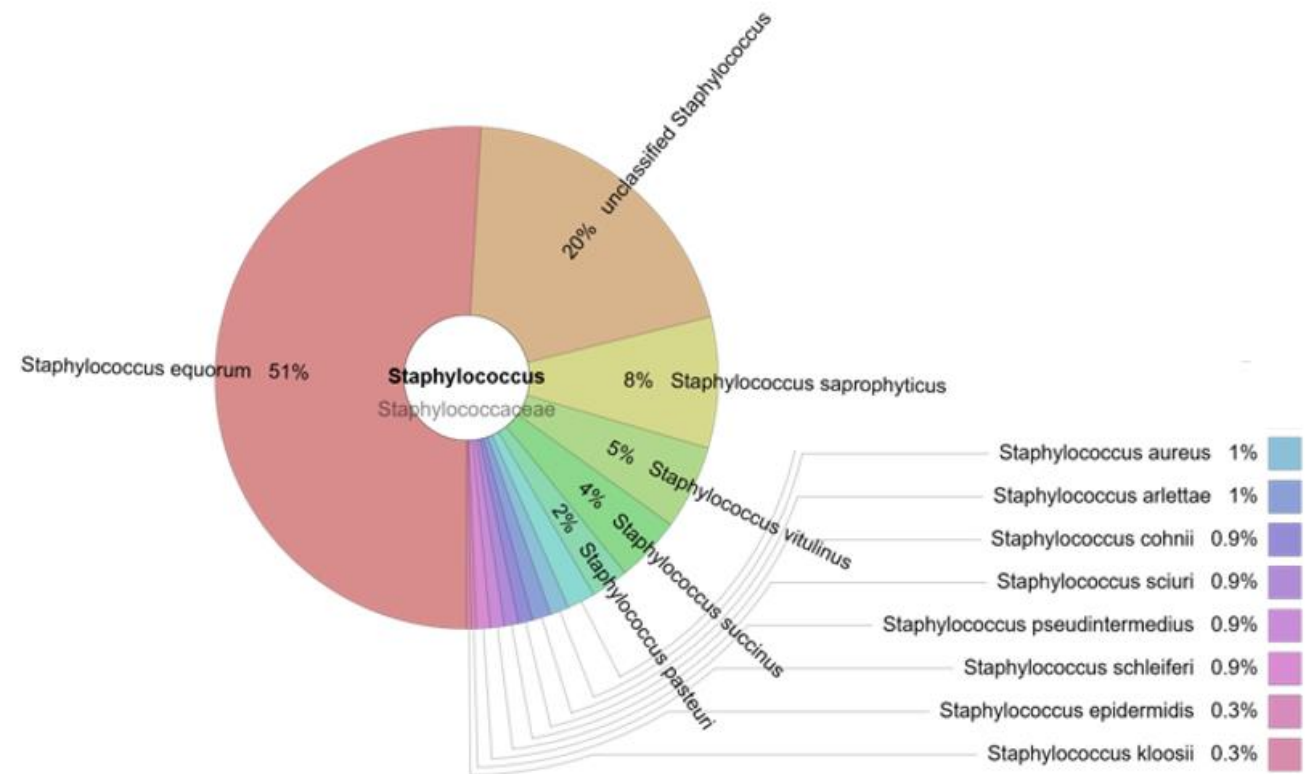

Fig. 2. The prevalence of staphylococci in the cloacal samples of gulls 


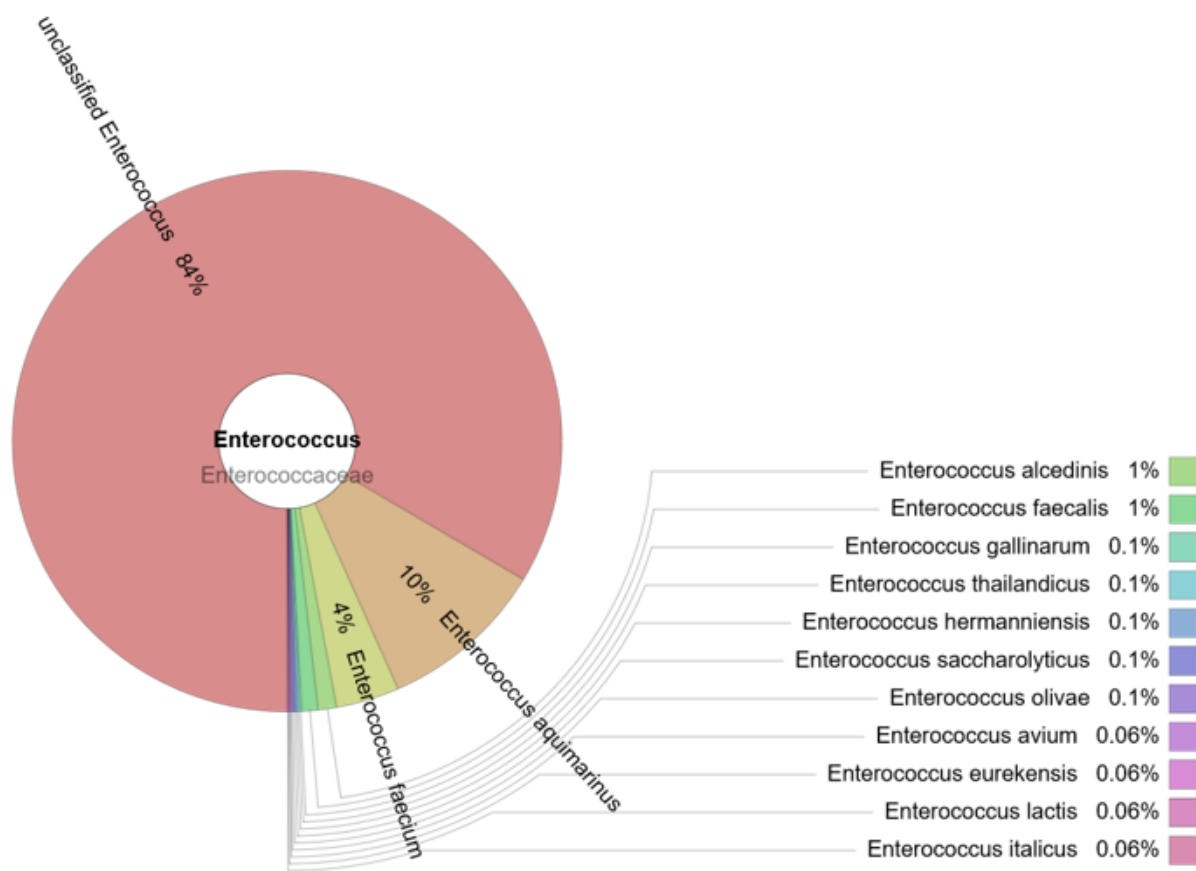

Fig. 3. The prevalence of enterococci in the cloacal samples of gulls

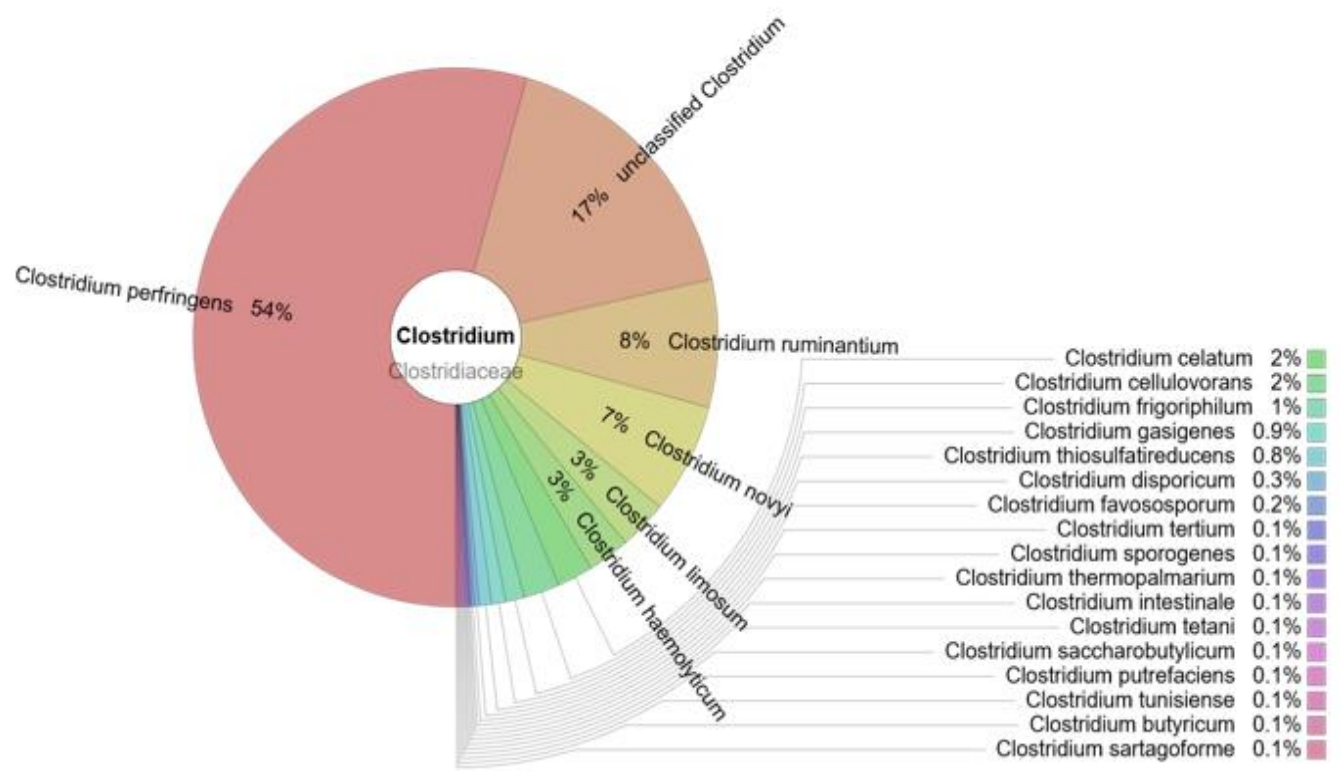

Fig. 4. The prevalence of clostridia in the cloacal samples of the gulls

Mycobacterium spp. In total, 20 different species of the Mycobacterium genus were detected, with the most frequently detected being $M$. chelonae (57\%), followed by $M$. mucogenicum (6\%) and M. hassiacum (2\%). No pathogenic species such as M. tuberculosis or $M$. avium were detected.

Antimicrobial susceptibility of the isolates and prevalence of the genes encoding antimicrobial resistance. The phenotypical resistance of Grampositive isolates was detected towards tetracycline, penicillin $\mathrm{G}$, oxacillin, sulphamethoxazole-trimethoprim, gentamicin, erythromycin, lincomycin, and chloramphenicol.
Resistance of the Gram-negative isolates was found for tetracycline, cefpodoxime, ceftazidime, cefotaxime, sulphamethoxazole-trimethoprim, streptomycin, kanamycin, gentamicin, and ciprofloxacin. The presence of the appropriate genes encoding antimicrobial resistance in cultivable bacteria isolated from gulls as well in total DNA extracted from their cloacal samples is presented in Table 2 .

Table 2 shows that the only single gene found exclusively in the total DNA was sul1 encoding resistance to sulphonamides. 
Table 2. The presence of the genes encoding antimicrobial resistance in cultivable bacteria and in total DNA from the cloacal samples of European herring gulls

\begin{tabular}{|c|c|c|c|}
\hline Antimicrobial class & Resistance genes tested & $\begin{array}{l}\text { Presence }(+) \text { or absence }(-) \text { of the genes in isolated } \\
\text { cultivable bacteria }\end{array}$ & $\begin{array}{l}\text { Presence }(+) \text { or absence } \\
(-) \text { of the genes in total } \\
\text { DNA }\end{array}$ \\
\hline \multirow{5}{*}{ Tetracyclines } & tet $\mathrm{A}$ & $+($ Staphylococcus, Enterococcus) & + \\
\hline & tet $\mathrm{B}$ & $+($ Acinetobacter, Klebsiella, Enterobacter $)$ & + \\
\hline & tet $\mathrm{K}$ & $+($ Staphylococcus $)$ & + \\
\hline & tet $\mathrm{M}$ & $+($ Enterococcus $)$ & + \\
\hline & tet $\mathrm{L}$ & - & - \\
\hline \multirow{11}{*}{ Beta-lactams } & tem & $+($ Acinetobacter, Pseudomonas, Klebsiella $)$ & + \\
\hline & $s h v$ & - & - \\
\hline & oxa 1 group & - & - \\
\hline & oxa 3 group & $+($ Pseudomonas $)$ & + \\
\hline & oxa 5 group & - & - \\
\hline & $c t x-\mathrm{M}$ & $+($ Acinetobacter, Klebsiella, Enterobacter $)$ & + \\
\hline & cmy & - & - \\
\hline & per & - & - \\
\hline & mecA & $+($ Staphylococcus $)$ & + \\
\hline & $m e c \mathrm{C}$ & - & - \\
\hline & blaZ & $+($ Staphylococcus $)$ & + \\
\hline \multirow{5}{*}{ Trimethoprim } & $d f r \mathrm{G}$ & $+($ Staphylococcus $)$ & + \\
\hline & $d f r \mathrm{~K}$ & - & - \\
\hline & $d f r 1$ & $+($ Escherichia $)$ & + \\
\hline & $d f r 5$ & - & - \\
\hline & $d f r 7$ & - & - \\
\hline \multirow{3}{*}{ Sulphonamides } & sul1 & - & + \\
\hline & sul2 & $+($ Escherichia, Enterobacter $)$ & + \\
\hline & sul3 & - & - \\
\hline \multirow{5}{*}{ Aminoglycosides } & strA & $+($ Escherichia $)$ & + \\
\hline & strB & $+($ Escherichia $)$ & + \\
\hline & $a a c\left(6^{\prime}\right)-I e-a p h\left(2^{\prime \prime}\right)-I a$ & $+($ Enterococcus $)$ & + \\
\hline & $\operatorname{aph}\left(3^{\prime}\right)-I I I a$ & $+($ Enterococcus $)$ & + \\
\hline & $\operatorname{ant}(6)-I a$ & $+($ Enterococcus $)$ & + \\
\hline \multirow{5}{*}{$\begin{array}{l}\text { Macrolides, } \\
\text { lincosamides and } \\
\text { streptogramins }\end{array}$} & erm $\mathrm{A}$ & $+($ Staphylococcus $)$ & + \\
\hline & erm $\mathrm{B}$ & $+($ Enterococcus $)$ & + \\
\hline & erm $\mathrm{C}$ & $+($ Staphylococcus $)$ & + \\
\hline & $m s r \mathrm{AB}$ & $+($ Staphylococcus $)$ & + \\
\hline & $m s r C$ & - & - \\
\hline \multirow{3}{*}{ Amphenicols } & cat $\mathrm{A} 7$ & $+($ Enterococcus $)$ & + \\
\hline & catA8 & - & - \\
\hline & catA9 & - & - \\
\hline \multirow{2}{*}{ (Fluoro)quinolones } & gyrA & $+($ Acinetobacter, Escherichia $)$ & + \\
\hline & $\operatorname{par} \mathrm{C}$ & $+($ Acinetobacter $)$ & + \\
\hline \multirow{2}{*}{ Vancomycin } & $\operatorname{van} \mathrm{A}$ & - & - \\
\hline & $\operatorname{van} \mathrm{B}$ & - & - \\
\hline
\end{tabular}

\section{Discussion}

We studied bacterial diversity in cloacal samples within a population of wintering European herring gulls with a tendency to feed in a municipal city dump. The variety of the microbiota was large with a clear dominance of the Catellicoccus genus that comprised half of the bacterial microorganisms in the samples. Previous data on the composition of the gull microbiota are scarce, but at least one study has been performed. In this study from 2008, Lu et al. (8) analysed the microbiota of different North American species of gulls, taking 282 faecal samples and using 16S rRNR sequencing. In total, 85 different operational taxonomic units representing 38 known bacterial genera were detected, with the highest detected prevalence being that of Catellicoccus marimammalium. The metagenomic studies using next generation sequencing (NGS) detected 75,756 reads and 697 different operational taxonomic units at the genus level in 10 samples of birds, proving the superiority of NGS in microbiome studies. Catellicoccus marimammalium is a Gram-positive and catalase-negative bacterium known as a resident in the gut of gulls specifically, and not in other bird families. This suggests that assays targeting this bacterial species might be an indicator of gull faecal pollution (8). Our study supports this finding and demonstrates that Catellicoccus marimammalium is ubiquitous in gulls not only in North America but also in the Western Palearctic.

We studied the composition of clinically important bacteria and detected opportunistic pathogens such as staphylococci, Enterobacteriaceae, Clostridium, and Pseudomonas. Human obligate pathogens were detected only in a very small number of reads (Salmonella enterica and Shigella spp.), campylobacters being the most highly prevalent. C. jejuni, however, was only a small part (6\%) within 
this genus. Brachyspira spp. were also detected, including $B$. pilosicoli. This anaerobic spirochaete colonises the large intestine of many host species. Infection is particularly problematic in pigs and adult poultry, resulting in colitis and diarrhoea but it is a health threat in humans as well (11). No pathogenic mycobacteria species nor chlamydia were detected. Among Clostridium spp., C. perfringens was the most prevalent species. The pathogenicity of this species depends on bacterium type and certain conditions within the host. This species, as most clostridia are, is abundant in soils and other environments. Thus, the role of gulls in the epidemiology of this genus is difficult to assess.

A wide variety of Enterobacteriaceae were prevalent in the gull cloacal material. They consisted of 20 genera, with the highest prevalence ascribed to clinically important constituents of this group such as Escherichia, Klebsiella, Yersinia, and Enterobacter. These genera are reservoirs of genes encoding antimicrobial resistance $(9,10,13)$.

Among Staphylococcus spp., S. equorum was the predominant species. It comprised half of the population of all staphylococci. Interestingly, this species is usually described as staphylococci associated with fermented food products (6). S. equorum is a new species identified in 1984, when it was isolated from the skin of healthy horses. Our findings suggest that there is too little knowledge about the natural prevalence of $S$. equorum and its taxonomic position including nomenclature. In our previous study, we detected $S$. equorum in a diseased dog (14). Another opportunistic pathogen ( $S$. aureus) was detected in gull cloacal samples. The small amount of $S$. auerues $(1 \%$ of all staphylococci) indicates that this bacterium was isolated accidentally, and in all likelihood it cannot be treated as a normal inclusion in the microbiota of European herring gulls.

Enterococcus was another common genus along with the other Gram-positive cocci in the tested material. The biggest part of the population of this genus $(84 \%)$ remained unidentified up to the species level. This demonstrates knowledge gaps in the current classification and nomenclature of animal enterococci. The most commonly investigated and clinically important species (E. faecalis and E. faecium) were detected in small amounts representing $1 \%$ and $4 \%$ of enterococci, respectively. Of the identified species, E. aquimarinus was predominant. There were only a few sequence reads for avian enterococci such as E. avium or E. gallinarum.

A wide variety of genes encoding antimicrobial resistance were detected in the microbiota of gulls. Genes detected in DNA of lysed isolates totalled 24, while 25 genes encoding resistance were found in total DNA. The genes representing isolated bacteria clearly coincide with the genes detected in the total DNA including non-cultivable bacteria. Only a single gene (sul1) representing resistance to sulphonamides was not detected in the isolates. This coincidence demonstrates that cultivable microbiota may represent the resistant genes prevalent within the microbiome of gulls. It is unclear, however, whether such coincidence can be found in other birds and mammals including humans. Therefore, similar studies should be performed in other host models. This study also revealed that highly resistant bacteria are prevalent in the faeces of European herring gulls, including methicillin-resistant staphylococci and extended spectrum beta-lactamases producing enterobacteria. Moreover, bacteria resistant to all antimicrobial classes tested (with the single exception of vancomycin) were found. Our study supports the findings of other authors who previously detected resistant bacteria in European herring gulls $(17,22)$.

In conclusion, Catellicoccus marimammalium remains the predominant microbiota in gulls despite the birds having dramatically changed their feeding habit. The gull can be treated as a reservoir of bacteria carrying a wide spectrum of genes encoding antimicrobial resistance, including those which can be horizontally transferred to other microbiota. Thus, the sanitary standards within the municipal dumps should be strengthened to minimise food opportunities for wild animals. Antimicrobial residues should be managed, and medical waste should be reduced.

This study also demonstrates the coincidence of the genes encoding antimicrobial resistance in cultivable bacteria and in the total bacterial DNA prevalent in cloacal material. Quantitative detection of bacteria using NGS for microbiome studies offers a clear view of the prevalence of separate taxonomic units of microorganisms. It also helps to separate native and allochthonic microorganisms in the microbiome of their host.

Conflict of Interests Statement: The authors declare that there is no conflict of interests regarding the publication of this article.

Financial Disclosure Statement: This research was funded by a grant (SIT-6/2015) from the Research Council of Lithuania.

Animal Rights Statement: The study protocol was approved by the Lithuanian Environmental Protection Agency.

\section{References}

1. Bauer A.W., Kirby W.M.M., Sherris J.C., Turk M.: Antibiotic susceptibility testing by a standardized single disk method. Am J Clin Pathol 1966, 45, 493-496.

2. Bonnedahl J., Järhult J.: Antibiotic resistance in wild birds. Ups J Med Sci 2014, 119, 113-116, doi: 10.3109/03009734.2014. 905663.

3. Caprioli A., Busani L., Martel J.L., Helmuth R.: Monitoring of antibiotic resistance in bacteria of animal origin: epidemiological 
and microbiological methodologies. Int $\mathbf{J}$ Antimicrob Agents 2000, 14, 295-301.

4. Clinical and Laboratory Standards Institute CLSI.: Performance standards for antimicrobial disk susceptibility tests; approved standard - eleventh edition. CLSI Documents M02-A11, Wayne, USA, 2012.

5. Dolejska M., Cizek A., Literak I.: High prevalence of antimicrobial-resistant genes and integrons in Escherichia coli isolates from black-headed gulls in the Czech Republic. J Appl Microbiol 2007, 103, 11-19.

6. Irlinger F., Loux V., Bento P., Gibrat J., Straub C., Bonnarme P., Landaud S., Monnet C.: Genome sequence of Staphylococcus equorum subsp. equorum Mu2, isolated from a French smearripened cheese. J Bacteriol 2012, 194, 5141-5142, doi: 10.1128/JB.01038-12.

7. Liakopoulos A., Mevius D.J, Olsen B., Bonnedahl J.: The colistin resistance mcr-1 gene is going wild. J Antimicrob Chemother 2016, 71, 2335-2336, doi: 10.1093/jac/dkw262.

8. Lu J., Santo Domingo J.W., Lamendella R., Edge T., Hill S.: Phyloegenetic diversity and molecular detection of bacteria in full faeces. Appl Environ Microbiol 2008, 74, 3969-3976.

9. Manges A.R.: Genomic epidemiology: revealing hidden reservoirs for Klebsiella pneumoniae. Clin Infect Dis 2015, 61, 900-902, doi: 10.1093/cid/civ433.

10. Mittal S., Mallik S., Sharma S., Virdi J.S.: Characteristics of $\beta$-lactamases and their genes (blaA and blaB) in Yersinia intermedia and $Y$. frederiksenii. BMC Microbiol 2007, 7, 25, doi: 10.1186/1471-2180-7-25.

11. Neo E., La T., Phillips N.D., Alikani M.Y., Hampson D.J.: The pathogenic intestinal spirochatae Brachyspira pilosicoli forms a diverse recombinant species demonstrating some local clustering of related strains and potential for zoonotic spread. Gut Pathog 2013, 5, 24, doi: 10.1186/1757-4749-5-24.

12. Radhouani H., Poeta P., Gonçalves A., Pacheco R., Sargo R., Igrejas G.: Wild birds as biological indicators of environmental pollution: antimicrobial resistance patterns of Escherichia coli and enterococci isolated from common buzzards (Buteo buteo). J Med Microbiol 2012, 61, 837-843, doi 10.1099/jmm.0.038364-0.

13. Rizi K.S., Peerayeh S.N., Bakhshi B., Rahbar M.: Prevalence of integrons and antimicrobial resistance genes among clinical isolates of Enterobacter spp. from hospitals in Tehran. Int J Enteric Pathog 2015, 3, 22531, doi: 10.17795/ijep22531.

14. Ruzauskas M., Couto N., Kerziene S., Siugzdiniene R., Klimiene I., Virgailis M., Pomba C.: Prevalence, species distribution and antimicrobial resistance patterns of methicillin- resistant staphylococci in Lithuanian pet animals. Acta Vet Scand 2015, 57, 27, doi: 10.1186/s13028-015-0117-z.

15. Ruzauskas M., Siugzdiniene R., Butrimaite-Ambrozeviciene C., Zymantiene J., Klimiene I., Vaskeviciute L., Mockeliunas R., Virgailis M.: Prevalence and characterization of multi-resistant Staphylococcus spp., isolated from poultry liver. J Food Safety 2016, 36, 508-514, doi: 10.1111/jfs.12270.

16. Ruzauskas M., Siugzdiniene R., Klimiene I., Virgailis M., Mockeliunas R., Vaskeviciute L., Zienius D.: Prevalence of methicillin-resistant Staphylococcus haemolyticus in companion animals: a cross-sectional study. Ann Clin Microbiol Antimicrob 2014, 13, 56, doi: 10.1186/s12941-014-0056-y.

17. Ruzauskas M., Vaskeviciute L.: Detection of the mcr-1 gene in Escherichia coli prevalent in the migratory bird species Larus argentatus. J Antimicrob Chemother 2016, 71, 2333-2334, doi: $10.1093 / \mathrm{jac} / \mathrm{dkw} 245$

18. Seputiene V., Bogdaite A., Ruzauskas M., Suziedeliene E.: Antibiotic resistance genes and virulence factors in Enterococcus faecium and Enterococcus faecalis from diseased farm animals: pigs, cattle and poultry. Pol J Vet Sci 2012, 15, 431-438, doi: 10.2478/v10181-012-0067-6.

19. Seputiene V., Povilonis J., Ruzauskas M., Virgailis M., Zlabys P., Suziedeliene E.: Quinolone resistance among Salmonella enterica and Escherichia coli in Lithuania. Biologija, 2006, 3, 74-78.

20. Shobrak M.Y., Abo-Amer A.E.: Role of wild birds as carriers of multi-drug resistant Escherichia coli and Escherichia vulneris. Braz J Microbiol 2014, 45, 1199-1209.

21. Smith S., Wang J., Fanning S., McMahon B.J.: Antimicrobial resistant bacteria in wild mammals and birds: a coincidence or cause of concern? Ir Vet J 2014, 67, 8, doi: 10.1186/2046-048167-8.

22. Stedt J., Bonnedahl J., Hernandez J., McMahon B.J., Hasan B., Olsen B., Drobni M., Waldenström J.: Antibiotic resistance patterns in Escherichia coli from gulls in nine European countries. Infect Ecol Epidemiol 2014, 4, 10.3402/iee.v4.21565, doi: 10.3402/iee.v4.21565.

23. Vredenburg J., Varela A.R., Hasan B., Bertilsson S., Olsen B., Narciso-da-Rocha C., Bonnedahl J., Stedt J., DaCosta P.M., Manaia C.M.: Quinolone-resistant Escherichia coli isolated from birds of prey in Portugal are genetically distinct from those isolated from water environments and gulls in Portugal, Spain and Sweden. Environ Microbiol 2014, 16, 995-1004, doi: 10.1111/1462-2920.12231 